\title{
Discursos de seguridad en Argentina y Brasil: un análisis desde la teoría de la securitización
}

\author{
María Eugenia Cardinale*
}

Artículo recibido: 14 de septiembre de 2019

Artículo aprobado: 24 de abril de 2020

Doi: https://doi.org/10.12804/revistas.urosario.edu.co/desafios/a.8236

Para citar este artículo: Cardinale, M. E. (2021). Discursos de seguridad en Argentina y Brasil: un análisis desde la teoría de la securitización. Desafios, 33(1), 1-41. https://doi.org/10.12804/ revistas.urosario.edu.co/desafios/a.8236

\section{Resumen}

Los gobiernos conservadores de Argentina y Brasil se han respaldado en discursos securitarios frente a amenazas o peligros calificados de graves y existenciales. Nos proponemos describir los discursos y las prácticas llevadas a cabo en nombre de la seguridad, y analizarlos a través de la teoría de la securitización, buscando identificar elementos propios de esta en ambas coyunturas. Para ello nos centramos en distinguir en las enunciaciones: actor securitizador, sujeto amenazante, audiencias habilitadoras y medidas extraordinarias implicadas. Estos elementos constituyen una guia para poder dilucidar si estamos ante un efectivo proceso de securitización en los dos casos bajo estudio. Este es un estudio descriptivo-interpretativo que se basa en la teoría de la securitización, seleccionando algunos de sus componentes, para el análisis de

\footnotetext{
* Universidad Nacional de Rosario, Universidad Nacional de Entre Ríos, Universidad de Buenos Aires: Grupo de Estudio sobre Política Exterior, Geopolítica y Defensa (Pogedef), Instituto de Estudios de América Latina y el Caribe. Correo electrónico: mariucardinale@ gmail.com. ORCID: https://orcid.org/0000-0001-9614-0267
} 
los casos de Mauricio Macriy Jair Bolsonaro, a modo de evaluar si estamos ante la aplicabilidad de dicho enfoque.

Palabras clave: discursos; seguridad; securitización; uso de la fuerza; Argentina; Brasil.

\title{
Security Discourses in Argentina and Brazil: An Analysis from Securitization Theory
}

\begin{abstract}
Conservative governments in Argentina and Brazil have relied on security discourses in order to face threats or dangers described as serious and existential. This study aims to describe the discourses and practices deployed in the name of security and to analyze them through the theory of securitization, seeking to identify elements of such developments in both countries. To do this, focus on identifying in the presidential statements: the securitizing actor, the referent subject, the enabling audiences and extraordinary instruments involved. These elements are a guide to interpreting whether we are facing an effective securitization process in both cases under study. This is a descriptive-interpretative study that relies on the theory of securitization. I use some of its components to analyze the cases of Mauricio Macri and Jair Bolsonaro, in order to assess the applicability of this approach.
\end{abstract}

Keywords: Security; discourses; securitization; use of force; Argentina; Brazil.

\section{Discursos de segurança na Argentina e no Brasil: uma análise desde a teoria da securitização}

\begin{abstract}
Resumo
Os governos conservadores da Argentina e do Brasil se têm respaldado em discursos securitários frente a ameaças ou perigos qualificados de graves e existenciais. Nos proporemos descrever os discursos e as práticas levadas a cabo em nome da segurança e analisa-los através da teoria da securitização, buscando identificar elementos próprios desta em ambas as conjunturas. Para isso, nos centramos em distinguir nas
\end{abstract}


enunciações: ator securitário, sujeito ameaçante, audiências habilitadoras e medidas extraordinárias implicadas. Estes elementos constituem uma guia para conseguir dilucidar se estamos ante um efetivo processo de securitização nos dois casos sob estudo. Este é um estudo descritivo-interpretativo que se baseia na teoria da securitização, selecionando alguns de seus componentes, para a análise de os casos de Mauricio Macri e Jair Bolsonaro, a modo de avaliar se estamos ante a aplicabilidade de dito enfoque. Palavras-chave: discursos; segurança; securitização; uso da força; Argentina; Brasil.

\section{Introducción}

El siguiente artículo se orienta al análisis de la intensificación de los discursos de seguridad en Argentina y Brasil en las presidencias de Macri y Bolsonaro, respectivamente, reconociendo que en ambas administraciones la seguridad operó como uno de los objetivos gubernamentales prioritarios.

En la Posguerra Fría, y más intensamente desde 2001, se abrió un campo de abordaje de la seguridad entendido como amplio y expansivo, cuyas características son: la condición interméstica, que desdibuja la diferencia tradicional entre seguridad pública y defensa, y las medidas respectivas. La multidimensionalidad no refiere exclusivamente a cuestiones estratégico-militares/territoriales, incorporando lo ambiental, lo social, la salud, entre otros. El foco de la seguridad internacional son las nuevas amenazas (no tradicionales, trasnacionales y asimétricas, que hacen uso de la violencia de forma diferente a la estatal o bien son sus vectores): las principales serían el narcotráfico, el terrorismo y el crimen organizado, también las migraciones, los riesgos ambientales, entre otros (Cardinale, 2017b, p. 131).

Aquello que se inició como un enfoque posible adquirió en la actualidad una posición hegemónica y es fuente de definición tanto en el mundo académico como a nivel gubernamental e internacional. En el plano hemisférico, Estados Unidos ha promovido esta interpretación de la seguridad frente a las tres nuevas amenazas centrales (priorizándose en años recientes las migraciones), enfatizando la condición 


\section{I María Eugenia Cardinale}

interméstica y la necesidad de utilizar las fuerzas armadas (FF. AA.) a nivel interno como opción eficiente.

Hasta el nuevo giro conservador de los gobiernos suramericanos (Cardinale, 2018a), la subregión no había adoptado como un todo dichas percepciones y en algunos casos, como Argentina, la posibilidad de involucramiento de las FF. AA. en tareas de orden interno generaba un fuerte rechazo, por razones históricas, constitucionales y culturales.

Desde 2011, el eje de las amenazas a la seguridad hemisférica ha sido el crimen organizado, promovido desde la administración Obama (White House, 2011) y continuado por la gestión Trump. A pesar de las diferencias de la última administración, para Latinoamérica, no hubo cambios significativos en las prioridades de seguridad. Lo distintivo de los gobiernos conservadores de Argentina y Brasil es haber tomado estas referencias y enfoques en su totalidad, a pesar de que parten de condiciones disímiles en violencia y criminalidad.

Frente a ello, nos preguntamos: ¿puede entenderse como 'movimiento securitizador' el creciente énfasis otorgado a la seguridad por ambos mandatarios suramericanos? Y, en ese caso, ¿qué elementos de los enfoques de la securitización nos acercan a una identificación de su desarrollo en los casos de Argentina y Brasil?

En primer lugar, abordaremos el marco teórico considerando la definición del concepto de securitización y tomando como eje la cuestión discursiva. Según la Escuela de Copenhague, en el origen de toda afirmación de seguridad estamos ante un acto del habla: donde una autoridad legítima designa una amenaza como urgente y existencial, y, con ello, habilita una serie de medidas extraordinarias para la seguridad y el uso de la fuerza.

Discutiremos el carácter performativo de los actos del habla, trayendo a consideración su cualidad dialógica; tal como ha planteado Lazzarato (2006), esto constituye un aporte en la interpretación de la categoría securitización en la literatura latinoamericana, generalmente centrada en las definiciones de la Escuela de Copenhague. El giro en 
la comprensión del discurso nos hablita a afrontar la problemática desde un punto de vista social e intersubjetivo, no meramente subjetivo; la seguridad se construye no solo a partir de quien enuncia una amenaza y la necesidad de securitización social concomitante, sino que depende de la respuesta o aquiescencia que dicho mensaje opera en las audiencias. Para este estudio, tanto en Argentina como en Brasil, la problematización de los discursos y movimientos securitarios nos permite considerar las audiencias securitizantes como partes constitutivas de la propia enunciación.

Para Lazzarato (2006), la enunciación es más que el mero discurso, incorporando en ella las evaluaciones afectivas, ético-políticas, y la convocatoria a determinadas fuerzas sociales para un posicionamiento favorable a lo enunciado. Este estudio se propone indagar si existe una efectivización de procesos de securitización social, a nivel doméstico, en Argentina y Brasil; en ese sentido, las consideraciones ético-políticas y afectivas de ambos mandatarios, representativas de una mirada conservadora, son determinantes para situar como un eje fundamental de gobierno a la seguridad.

De los componentes propios de un proceso de securitización tomamos para este estudio: los discursos de seguridad utilizados durante las respectivas campañas electorales y su intensificación a partir de la asunción del mando en ambos casos. Se busca reconocer los sujetos amenazantes y el objeto referente de la seguridad. Segundo, las medidas tomadas como urgentes en torno a las amenazas identificadas (crimen organizado en Brasil y narcotráfico en Argentina) al poco tiempo de asumir sus mandatos. En este sentido, dos cuestiones resaltan: el decreto de Bolsonaro para ampliar la habilitación para la adquisición y tenencia de armas de fuego, por ciudadanos/as particulares; y la declaración de un estado de emergencia en seguridad en Argentina en 2016.

En tercer lugar, se contrasta tanto el discurso securitario como los instrumentos legales y las prácticas que se habilitaron con datos objetivos sobre violencia en cada territorio nacional (utilizando datos estadísticos elaborados por las Naciones Unidas y otras organizaciones). 


\section{I María Eugenia Cardinale}

Por último, en términos de contexto y marco externo entendemos que los discursos y las tendencias a la securitización social en Brasil y Argentina pueden leerse como un reforzamiento de los intereses domésticos, en detrimento de la cooperación regional en seguridad - tal como se expresara en el Consejo de Defensa Suramericanoa la par de un redireccionamiento de la cooperación en seguridad y defensa hacia relaciones bilaterales con Estados Unidos.

Este es un estudio descriptivo-interpretativo que se basa en la teoría de la securitización, seleccionando algunos de sus componentes, para el análisis de dos casos concretos, a modo de evaluar si estamos ante la aplicabilidad de dicho enfoque.

\section{Securitización, definiciones y abordajes}

Desde la formulación original de la securitización por Waever y Buzan (referentes de la Escuela de Copenhague), mucho se ha puesto en discusión en las RRII. En la definición de los autores hay un doble reconocimiento teórico-epistemológico: 1) su identificación con los enfoques constructivistas ha llevado a explorar la seguridad y las relaciones internacionales como no 'naturales' o autógenas, sino como fenómenos en construcción permanente mediante las propias interacciones de los agentes; 2) toman como referencia de análisis, "como método, el análisis postmoderno del discurso" (Tello, 2011), cuya base serán las propuestas de Austin y Searle en el estudio de los actos del habla para la relación entre lenguaje y realidad.

Frente a los tradicionales estudios de seguridad, materialistas y objetivistas, la búsqueda por complejizarlos y ampliar caminos de interpretación dio lugar a una diversificación epistemológica y metodológica. Así, Buzan y Hansen (2009) entienden que existen tres tipos de enfoques principales para el estudio de la seguridad: objetivistas; subjetivistas y discursivos. Aquí interesan estos últimos:

Security is, argues the Copenhagen School, a speech act and "by saying 'security', a state representative declares an emergency 
condition, thus claiming a right to use whatever means are necessary to block a threatening development" (Buzan et al., 1998, p. 21; see also Wæver, 1995). What is central to security analysis is thus understanding the process through which particular 'threats' manifest themselves as security problems on the political agenda. 'Threats' in that sense are 'objective' when they are accepted by significant political actors, not because they have an inherent threatening status. Security is, in short, a self-referential practice (Buzan et al., 1998, p. 24, en Buzan \& Hansen, 2009, p. 34).

Cuando mencionamos los actos del habla performativos nos referimos a condiciones donde el lenguaje crea realidad. Un enunciado de ese tipo supone que no solo está describiendo la realidad, sino que estamos ante la posibilidad de transformarla (Balzacq et al., 2015). Lazzarato (2006) afirma que una enunciación performativa no describe algo (una acción), sino que al decirla la realiza: "Declaro abierta la sesión", "Está usted condenado" (p. 21). Toda enunciación performativa comporta una 'obligación social'.

Los autores de la Escuela de Copenhague se refieren precisamente a este carácter performativo del lenguaje a la hora de abordar la seguridad. Así lo define Buzan: "Security has a particular discursive and political force and is a concept that does something — securitiserather than an objective (or subjective) condition" (Buzan \& Hansen, 2009, p. 231).

La fuerza de la seguridad reside en su capacidad para crear realidad con su sola enunciación o apelación. McDonald (2008) sostiene: "In this framework, language itself becomes security in the sense that particular forms of language — spoken or written in a particular context-constitute security" (p. 568).

Por lo tanto, para examinar un "movimiento securitizador" (Eissa, 2018) partimos de la enunciación realizada frente a una amenaza determinada, es decir, nos acercamos al proceso identificando el 'actor securitizador' y su discurso, luego, hacia quién se dirige y contra qué actores subyacentes a la amenaza. 


\section{I María Eugenia Cardinale}

Para la Escuela de Copenhague, securitizar un asunto o sector social implica quitarlo de los canales políticos regulares para tratarlo como condición extraordinaria, con instrumentos excepcionales, con lo que se extrae de la deliberación política ordinaria (Buzan et al., 1998). Es importante observar que el discurso de construcción de las amenazas a la seguridad está influenciado por la historia del Estado, su posición geográfica y estructural dentro del sistema internacional y la reacción que ese discurso genera en los otros/as tanto a nivel doméstico como internacional (Buzan \& Hansen, 2009). Teniendo esto en cuenta se comprenden mejor los conceptos esenciales que constituyen los elementos de securitización (Balzacq et al., 2015):

1. Actor securitizador: es fundamental el grado de legitimidad que tiene ese actor en el grupo social de pertenencia o en la sociedad civil en su conjunto, porque, para que su discurso constituya seguridad, la amenaza y las acciones propuestas necesitan obtener consenso. Buzan (1998) sostiene que, si bien, en principio, cualquiera puede operar como actor securitizador, más comúnmente son los líderes políticos, las burocracias, los gobiernos y grupos de presión los que cuentan con la legitimidad suficiente para obtener apoyos.

2. Sujeto referente (referent subject)/ sujeto amenazante: quién profiere la amenaza. Nos encontramos ante supuestos actores concretos detrás de fenómenos complejos y difusos; en América del Sur, en general, hablamos de crimen organizado y narcotráfico, y en menor medida de terrorismo.

3. Objeto referente: qué o quién está siendo amenazado. A quién o qué queremos proteger de ese peligro y por qué (al Estado, la ciudadanía, la región).

4. La audiencia: lo más importante por tener en cuenta es el sector específico de esa audiencia que otorga el consenso y, por lo tanto, da lugar a la securitización y sus acciones. Balzacq et al. (2015) van a denominarla "audiencia habilitadora" y Oelsner (2009) refiere a esta como "audiencia securitizante".

5. Contexto: tanto interno como externo. Esta noción emerge con el giro sociológico dado al concepto de securitización por parte de otras corrientes teóricas de las RRII, que veían 
falencias en la propuesta original. Se incorporó el análisis del contexto social —utilizando aportes de Bourdieu y Foucault-, para reflexionar sobre el capital simbólico y cultural de una sociedad que pretende securitizarse, es decir, la 'visión del mundo' a la que se apela y las bases prácticas en las que se sostiene. Por lo tanto, hacen énfasis en la securitización como acto pragmático, relacional, en tanto fenómeno colectivo y, mayormente, intersubjetivo (Tello, 2011; Balzacq et al., 2015). Debemos mirar en dónde se inscriben las prácticas securitarias, el 'repertorio semántico' que facilita la securitización de un tema. Para Buzan (2009), hablamos de condiciones facilitadoras de securitización.

6. Adopción de políticas: medidas extraordinarias —en su mayoría-, en lo que atañe al uso de la fuerza, restricciones temporales a libertades y derechos, incremento de la vigilancia y control poblacional, entre otras.

De acuerdo con Tello (2011), la seguridad como acto discursivo se convierte en realidad cuando la audiencia la reconoce como verdadera. La securitización es un proceso intersubjetivo, estamos ante una realidad "que se crea a sí misma en la interacción de los sujetos —actor securitizador y audiencia - y objetos — referente a securitizar- que la informan" (p. 193).

Aquí nos proponemos entender los actos del habla como dialógicos, no como performativos (productivos). Siguiendo a Lazzarato (2006), quien retoma a Bajtin, todo acto del habla es social, no solamente el denominado performativo, es decir que toda enunciación compromete una "obligación social", opera como utilización estratégica, dialógica, son "acciones sobre acciones posibles", abiertas "a la indeterminación de la respuesta-reacción del otro (de los otros)”. El autor da ejemplos enunciativos que sirven para pensar los discursos de seguridad: "[...] designa amigos y enemigos. [...] Busca aliados, quiere reconfigurar el espacio político convocando a los demás, [...] obligándolos a posicionarse” (Lazzarato, 2006, p. 23). 
Todo acto del lenguaje tiene una naturaleza dialógica: un enunciado es siempre, en vinculación a otro enunciado, una respuesta que busca problematizarlo, consolidarlo o cuestionarlo. Los locutores son activos y libres, por eso las respuestas, los acontecimientos y el propio enunciado no están predeterminados como en el performativo. En su misma concepción incluye a las audiencias porque sustrae el acto del habla de una esencia exclusivamente lingüística para sumar las evaluaciones afectivas, ético-políticas, y las fuerzas sociales que trascienden al lenguaje, pero que son inmanentes al enunciado y a las reacciones/respuestas que este suscita (Lazzarato, 2006, p. 9).

Integramos, además, el aporte realizado por los enfoques posestructuralistas en RRII al incorporar los estudios lingüísticos: hablar de políticas de seguridad es reconocer que se trata fundamentalmente de la construcción de un Otro radicalmente diferente, inferior y amenazante (Buzan \& Hansen, 2009). La designación del Otro/a que se constituye en peligro no es únicamente hacia identidades o culturas externas al propio Estado, sino que suele considerarse otro/a interno/a. "[...] these were "located in different sites of ethnicity, race, class, gender, or locale" (Campbell, 1990, p. 270, citado en Buzan \& Hansen, 2009, p. 159). Esta idea de posicionar a sectores de la sociedad civil como peligrosos la entendemos como clave para analizar los discursos securitarios en Brasil y Argentina.

En la bibliografía latinoamericana encontramos una serie de trabajos que proponen analizar problemáticas regionales a partir de la teoría de la securitización y las categorías de la Escuela de Copenhague. Es pertinente destacar que en todos los estudios revisados el actor securitizador es el gobierno nacional, donde se examinan los discursos y las medidas desplegadas en los procesos de securitización. Los análisis oscilan entre consideraciones regionales/subregionales compartidas de securitización (Tickner, 2005; Oelsner, 2009; Baeza, 2016), temáticas particulares securitizadas (en lo doméstico, regional o hemisférico) (Frenkel, 2019; Eissa, 2018) y el peso de Estados Unidos en los procesos securitizadores de zonas o temáticas en Suramérica (Frenkel, 2019; Tickner, 2005; Baeza, 2016). 
Este artículo se propone indagar si existe un efectivo proceso de securitización social, a nivel doméstico, en Argentina y Brasil. Por lo tanto, no realizamos un recorte temático, al contrario, consideramos que la designación del sujeto amenazante sirve a los fines de desarrollar un proceso de securitización a escala nacional antes que como destino exclusivo de las acciones. Entendemos las consideraciones ético-políticas y afectivas de ambos gobiernos, el 'giro conservador', como determinantes para priorizar la seguridad y las medidas extraordinarias concomitantes. Por último, el análisis se centra en los discursos y su papel como instrumento principal de legitimidad para tomar decisiones públicas.

\section{Movimientos securitarios en Argentina y Brasil}

\section{La seguridad y las campañas electorales}

Es necesario remarcar la posición político-discursiva extrema de Bolsonaro. Esta es una diferencia medular con los enunciados de Macri y su espacio de pertenencia política, que han buscado, no siempre con éxito, respaldarse en un lenguaje acorde con la institucionalidad democrática.

Sin embargo, en ambos casos estamos frente a propuestas conservadoras, de derecha, cuya principal herramienta de campaña ha sido la diferenciación con los gobiernos progresistas anteriores, por su supuesta corrupción y desatención a la seguridad pública.

La alianza Cambiemos (frente político gobernante) durante la campaña electoral de 2015 definió tres ejes políticos principales (Clarín, 2015): 1) pobreza cero, 2) lucha contra el narcotráfico, 3) unir a los argentinos (dada la presunta división ideológica y social creada por el Frente para la Victoria).

Lo llamativo de seleccionar un elemento securitario como el narcotráfico, en tanto eje gubernamental posible, no se condice con la situación argentina en cuanto al fenómeno, excepto en ciudades específicas. Argentina no cuenta con grandes grupos ilegales productores de sustancias ilegales, capaces de controlar amplias franjas de 
territorio - como en los casos de México y Colombia-, o con un recrudecimiento de la violencia a manos privadas como en Centroamérica, incluso en el propio Brasil (Tokatlián, 2016a, 2019).

Los discursos sobre seguridad fueron intensamente promovidos por los medios de comunicación durante los últimos años del gobierno de Fernández. Un tema que fue instalado en la agenda pública por los mass media preponderantes y que se incorporó a la enunciación del candidato presidencial de Cambiemos en 2015.

Bolsonaro definió cinco promesas (BBC Mundo, 2018a) para su futuro gobierno: 1) flexibilizar los controles para la posesión de armas; 2) mayores licencias para disparar, con menores restricciones, a las fuerzas de seguridad; 3) terminar con el "adoctrinamiento" en las escuelas (todo lo vinculado a DD. HH. y educación sexual integral); 4) definir la ocupación de tierras como terrorismo (particularmente considerando el Movimiento Sin Tierras); 5) no otorgar más concesiones de tierras a pueblos originarios.

Las promesas 1, 2 y 4 se vinculan directamente con un discurso securitario, alegando que estas medidas ayudarían a la ciudadanía a la "legítima defensa" de su propiedad, así como a una "protección" a las fuerzas de seguridad (FF. SS.) durante su accionar frente al crimen organizado. En el caso de Brasil, el aumento de los niveles de violencia asociados a la criminalidad privada organizada constituye un problema relevante - intensificado en los últimos años— que sirvió de base para los discursos de campaña.

\section{Gobiernos conservadores y ¿securitización? El caso de Argentina}

Mauricio Macri asume la Presidencia de Argentina en diciembre de 2015; el 21 de enero de 2016 se establecía el Decreto 228 declarando la emergencia en seguridad pública por un año. Esto evidencia el rol central que cumplirá la seguridad para el mandato de Cambiemos. Ahora bien, ¿con qué fundamentos se declara esta emergencia y para qué? 
Dentro de las justificaciones del decreto se encuentran: la espiral creciente de delito, la gravedad de la trata de personas, y, luego, dedica gran parte al problema del narcotráfico, tal como se había estipulado en campaña.

Que es decisión de este Gobierno combatir el narcotráfico con el máximo rigor, a fin de dar acabada respuesta a la profunda preocupación por este tema evidenciada por la ciudadanía.

Que el narcotráfico y sus delitos asociados, no quedan atrás en este escenario y constituyen una irrenunciable y excluyente cuestión de Estado al encontrarse inextricablemente ligados a la inseguridad. [...] Que la problemática del narcotráfico no sólo afecta a la salud y la seguridad ciudadana, sino que importa una violación a la soberanía nacional en tanto se trata de un crimen cuya naturaleza es claramente transnacional.

Que tales circunstancias ameritan adoptar las medidas que permitan extremar el uso de los recursos del ESTADO NACIONAL en orden a enfrentar los flagelos señalados (Decreto 228/2016).

Alega, además, la necesaria respuesta a los reclamos de la sociedad sobre seguridad y la conexión entre todos los delitos complejos bajo el paraguas del crimen organizado transnacional. Utilizan como base una acordada de la Corte Suprema de Justicia, y todo esto es vinculado con el control de fronteras y la creación de un programa concreto para los límites fronterizos del norte del país; allí resalta la cuestión de vuelos no identificados — que puedan estar asociados a ilícitos-y la habilitación a derribarlos por su sola condición de 'sospechosos' (con pasos por cumplimentar previos al derribo). Esto ha sido cuestionado como "ejecución extrajudicial” (Tokatlián, 2016b).

De acuerdo con InSight Crime, organización que realiza un seguimiento de la situación de inseguridad en América Latina — vinculada a delitos y violencia-, para 2019: "A pesar del prominente papel de Argentina como centro de lavado de dinero y punto de tránsito y consumo de drogas, el país no padece los altos niveles de violencia que afectan a otras naciones latinoamericanas” (InSight Crime, 2019). 
Para el año 2015, la tasa de homicidios, con un incremento casi constante desde 2012, era de 8,8 por cada 100000 habitantes. Estos niveles no eran homogéneos en todo el territorio nacional, sino que se concentraban en dos provincias - y en grandes ciudades, dentro de ellas: Buenos Aires y Santa Fe (Gallo, 2015)—. Hablamos de situaciones de violencia focalizadas y relacionadas con grupos dedicados a la venta de drogas ilegales. Por otra parte, Argentina estaba en 2015, y está aún hoy, en un nivel muy bajo de violencia comparada con el resto de Latinoamérica. En la página oficial de la UNODC, ${ }^{1}$ la tasa de homicidios para 2014 era de 7,5 por cada 100000 habitantes. Sin embargo, en su primer discurso como Presidente ante el Parlamento, Macri afirmaba:

Una de las principales responsabilidades del Estado es cuidar la seguridad de los argentinos. Nos encontramos con un Estado débil, con fuerzas de seguridad mal equipadas, mal remuneradas, mal entrenadas y maltratadas. Un Estado con poca o nula capacidad de investigar y prevenir. Entre la incompetencia y los traumas ideológicos, casi todas las políticas de seguridad de los últimos años han sido un fracaso. [...] Tenemos un muy preocupante panorama en materia de violencia, crimen, tráfico de drogas y de personas, producto de estas malas políticas. ¡La inseguridad no es una sensación! Es un flagelo que ha sido negado sistemáticamente, generando otra violencia, la verbal: la denigración de sentir que el Estado no sólo no te cuida, sino que te falta el respeto.

Desde 2008 no se publican los datos del delito. Los primeros datos que pudimos relevar nos indican que estamos en 3.400 homicidios por año, lo que representa un aumento del 40 por ciento respecto de 2008.

Hoy, la Argentina es un país próspero para los narcotraficantes. Somos un país que recibe droga, la transforma, la vende internamente y la exporta a Europa, África, Asia, Australia, Medio Oriente y a países vecinos como Chile y Uruguay.

Según la Oficina de las Naciones Unidas contra la Droga y el Delito, la Argentina es el tercer país proveedor mundial de cocaína

\footnotetext{
1 Oficina de las Naciones Unidas contra la Droga y el Delito, por su sigla en inglés.
} 
$[\ldots]$ Nuestras fronteras están virtualmente indefensas [...] ( $\mathrm{La}$ Nación, 2016).

Los datos dados por el Presidente no se condicen con los de la ONU, primero porque se contaba con estadísticas criminales, resultando la tasa de homicidios de 2014 menor que la de 2013. En el informe World Drug Report 2015 de la UNODC, Argentina es mencionada en el tráfico ilícito de cocaína como ruta secundaria, las principales rutas de distribución global son Brasil y la Región Andina. La importancia de Argentina en el tráfico ilegal es, en concreto, hacia Europa y no es catalogada como productora, aunque sí se reporta la existencia de laboratorios para procesamiento de hoja de coca/pasta base para 2013. Por otro lado, las mayores incautaciones de droga en los últimos diez años han sido de marihuana (UNODC, 2015). Tokatlián (2016a) contrapone estos datos a otras fuentes, como el Centro Europeo de Monitoreo de Drogas y Adicción a las Drogas o los informes periódicos del Departamento de Estado de Estados Unidos de su estrategia antinarcóticos, para afirmar que no hay evidencia cierta para situar al país como tercer exportador de cocaína del mundo.

Estamos, por lo tanto, frente a un enunciado impregnado de evaluaciones afectivas, ético-políticas, y de convocatoria a determinadas fuerzas sociales que se espera atraer y convencer. La amenaza existencial es identificada: el narcotráfico; las medidas extraordinarias son dictadas a los pocos días de asunción del gobierno al declararse la emergencia en seguridad pública. Entendemos estos hechos como el paso de un 'movimiento securitizador' a una securitización, que se irá profundizando a lo largo de la gestión Cambiemos.

América Latina es considerada desde hace varios años como la región más violenta del mundo. En el Estudio mundial sobre homicidio publicado en 2019 por la UNODC, se reafirma este dato: "Sólo tiene el 13\% de la población mundial, pero se registran el $42 \%$ de todas las muertes violentas". Los principales países donde se intensificó esta violencia son El Salvador, Venezuela, México y Brasil (Clarín, 2019). Los responsables primarios de esta escalada de violencia, de acuerdo con el informe, serían la desigualdad social y el crimen organizado. 
Argentina está al final de la tabla elaborada por el organismo con 5,2 homicidios cada 100000 habitantes; si bien la situación sigue estando por encima de la media mundial, es muy baja con respecto a los Estados con mayores niveles de violencia, solo la preceden Paraguay y Chile con índices más bajos (UNODC, 2019).

Ahora bien, todo movimiento securitizador requiere de consenso para considerarse exitoso y, por lo tanto, iniciado explícitamente. Haber colocado la cuestión de la lucha contra el narcotráfico como eje de campaña electoral otorga legitimidad de origen al gobierno, contando con el respaldo del $51 \%$ de la población al momento de ganar la elección. Entendemos que en relación con el narcotráfico se ha conseguido el consenso necesario para un proceso de securitización.

Se ve reflejado en el apoyo del Parlamento para las medidas securitarias, en el respaldo de los gobiernos provinciales para el despliegue de fuerzas federales de seguridad en sus territorios, en los resultados de encuestas permanentes que realizara el gobierno y donde afirman obtener el aval de la población para implementar 'mano dura' contra el delito.

Si observamos la página oficial de la Casa Rosada, encontramos los instrumentos para identificar al gobierno como actor securitizador y también las medidas extraordinarias adoptadas. Un apartado específico sobre Seguridad y narcotráfico muestra el despliegue de las FF. SS. a lo largo de todo el territorio nacional y, en especial, en las zonas ya mencionadas.

Afirma: "Policía Federal Argentina (PFA) se desplegó como nunca antes en su historia en todo el territorio. Esta nueva Policía Federal Argentina está orientada hacia la investigación criminal y el delito complejo, distribuida en ocho (8) Agencias Regionales Federales por todo el país" (Casa Rosada, 2019). Se especifica el trabajo conjunto de fuerzas federales y provinciales en OCAF (operativos conjuntos abiertos de fronteras), dando cuenta de las incautaciones efectuadas. 
Señalamos dos cuestiones: las mediciones de los logros en seguridad son estrictamente cuantitativos, por ejemplo, hay en la página un cuadro comparativo de incautaciones de droga a lo largo de la gestión Cambiemos; y, en segundo lugar, muestra la contradicción entre el discurso presidencial y los hechos, las mayores incautaciones se dan en las fronteras o en rutas cercanas a ellas y son de marihuana, Argentina no parece ser la tercera proveedora mundial de cocaína, como sostenía Macri en 2016.

Otro programa que se expone es el de Barrios Seguros, esto es el despliegue de efectivos federales en barrios (generalmente pobres) de las ciudades con las mayores tasas de violencia, como el conurbano bonaerense o la provincia de Santa Fe. Se define como programa de "pacificación” (Casa Rosada, 2019).

Una de las cuestiones principales que pueden reconocerse como securitización " [...] es que las primeras medidas excepcionales están asociadas a un mayor margen de control en las calles y en las vidas personales que, generalmente, involucra un aumento de la presencia de la fuerza policial o militar en la cotidianeidad" (Cardinale, 2017a, p. 17).

Lo cierto es que estamos ante un proceso "ininterrumpido de endurecimiento represivo por parte de la gestión securitaria del gobierno argentino", que se inicia con la represión de la protesta social (legitimada y legalizada), se refuerza con la "intensificación de la presencia de las fuerzas de seguridad nacionales en todo el territorio nacional" y se profundiza definitivamente "con la denominada 'Doctrina Chocobar', el involucramiento de las Fuerzas Armadas en conflictos internos, la habilitación del uso de armas de fuego sin dar orden de alto para la policía [...]" (Assusa, 2019, p. 3).

Por otra parte, existieron intentos de securitizar la relación con el pueblo originario mapuche en el sur del país. Frente a sus reclamos y manifestaciones por tierras — consideradas ancestrales—, se les calificó, desde el Ministerio de Seguridad, como "terroristas". Esto da cuenta de lo mencionado por Assusa (2019) como represión de la protesta social, 
ya que, en 2017, ante un corte de rutas por la comunidad mapuche en la provincia de Chubut, el gobierno decide la intervención de gendarmería (FF. SS. especializadas) ${ }^{2}$ para su desalojo por la fuerza.

El actor securitizador en este caso es, para Eissa (2018), tanto el gobierno nacional como los medios de comunicación hegemónicos, colocando en la agenda pública la noción de terrorismo y/o agrupaciones armadas operando en el sur, tal como se refleja en una declaración de los ministros de Seguridad y de Justicia, a modo de justificar el accionar de las FF. Ss.: "El Estado, el juez, las fuerzas de seguridad, y los ministerios de Seguridad y de Justicia llevan adelante una acción legítima, enmarcada en la ley frente a la acción violenta, ilegal e inaceptable para la democracia de un país que quiere vivir en paz, en referencia a los grupos armados que han tomado la violencia como forma de acción política" (UNO Entre Ríos, 2017, citado en Eissa, 2018, p. 52).

Este discurso que el autor interpreta como movimiento securitizador entendemos aquí que no fue exitoso porque no obtuvo el reconocimiento de la ciudadanía para definir el conflicto con los pueblos originarios en estos términos.

Otro elemento clave de securitización lo hallamos en la habilitación a las FF. AA. para participar en la lucha contra el narcotráfico. Ya en un discurso ante el Colegio Militar de la Nación en mayo de 2016 el Presidente expresaba:

Necesitamos que las Fuerzas Armadas se adapten a las demandas y requerimientos del siglo XXI, primero ayudándonos a nuestra política exterior, participando en misiones de paz.

Lo segundo, $[\ldots]$ debido al descuido que hemos tenido como humanidad respecto al medio ambiente, el cambio climático que

\footnotetext{
2 En ese escenario de desalojo de la protesta se produce la desaparición por más de 70 días de Santiago Maldonado, un artesano que participaba de la protesta en apoyo a la comunidad mapuche sin formar parte étnicamente de ella. Se viralizó a nivel internacional el reclamo por su aparición con vida y los cuestionamientos a las acciones de gendarmería.
} 
estamos sufriendo ha traído a nuestra agenda, ya mensual, distintos tipos de emergencias y catástrofes, y el pueblo argentino necesita de sus Fuerzas Armadas ahí, listas para reaccionar rápido y asistir, como también necesitamos que trabajemos juntos contra las amenazas del terrorismo (Casa Rosada, 2016).

La noción de unas FF. AA. para el siglo XXI hace referencia explícita al modelo hegemónico hemisférico de seguridad promovido por Estados Unidos, centrado en las nuevas amenazas y en consideraciones intermésticas, que habiliten a dichas fuerzas para seguridad interior, incluso en la problemática particular de catástrofes naturales que ha indagado Frenkel (2019).

Finalmente, mediante el Decreto 683/2018, el Presidente facultó a las FF. AA. para tareas de orden interno; concretamente se utilizaron en la frontera norte del país en la lucha contra el narcotráfico (el gobierno anterior ya había contado con 'apoyo logístico' militar a las FF. SS. en acciones fronterizas). En la actualidad se utilizan para tareas de interdicción, vigilancia y entrenamiento a las fuerzas de seguridad, aunque los expertos advierten sobre su despliegue para control directo de la seguridad en ciertas fronteras. Se rompe con una tradición de la democracia argentina, que desde su recuperación en 1983 prohibió que las FF. AA. realicen tareas internas, separando estrictamente la defensa de la seguridad pública (Sain, 2018).

Podemos vincular esto a un discurso 'flexible' del gobierno nacional con respecto a la última dictadura militar, esgrimido también en campaña. Bolsonaro recurre a argumentos más explícitos en defensa de la dictadura brasilera, pero, de igual modo, parece haber una coincidencia entre ambos mandatarios en este aspecto. Macri definió, en campaña, las políticas de derechos humanos como un "curro"; él y miembros

\footnotetext{
3 Según esta lógica, la defensa y ampliación de los dd. hh. es utilizada como un negocio privado por partidos políticos, organizaciones de la sociedad civil y el anterior gobierno, siendo definida como particularmente arbitraria en relación con los juicios a exmilitares participantes del gobierno dictatorial por crímenes de lesa humanidad.
} 
de su espacio político han negado/cuestionado que el número de personas desaparecidas durante el gobierno de facto sea el referido por las organizaciones de derechos humanos, 30000 —un argumento utilizado por los propios militares involucrados en la dictadura para justificar su accionar-; también definió dicho período histórico como "guerra sucia” (calificativo utilizado por la Junta Militar para la acción represiva, alegando la necesidad de enfrentarse a un "enemigo interno" como el "comunismo"), en lugar de recurrir a categorías como dictadura o terrorismo de Estado (La Capital, 2016).

La lógica punitivista ha ido in crescendo a medida que se acercaban las elecciones generales de 2019. De acuerdo con Durán Barba, el asesor de publicidad y campaña del gobierno: "Hemos medido la angustia frente al delito. Mucha gente, sobre todo de los sectores populares, siente que no puede salir de su casa. Por eso desarmar a la policía es poco popular. La gente pide que se reprima brutalmente a los delincuentes" (Perfil, 2018).

Dichos enunciados se producen bajo el impulso, por parte del Ministerio de Seguridad, a la denominada 'Doctrina Chocobar'. Es una medida similar a la impulsada por Bolsonaro en Brasil, que en Argentina fue desplegada a partir de un caso: cuando un policía de apellido Chocobar asesinó a un ladrón desarmado en la Capital Federal. El gobierno de Cambiemos salió a respaldar el accionar policial de quien fuera procesado en la justicia argentina, y lo recibió "como un héroe" en la Casa Rosada (Perfil, 2018). Más que las declaraciones presidenciales, fue esta demostración simbólica la que dejó en claro la posición gubernamental, la foto del encuentro operó como mensaje.

Ese antecedente habilitó un nuevo protocolo de actuación para las FF. Ss. federales, tal como fue ratificado por el jefe de gabinete: "Podrán emplear armas de fuego en casos de defensa propia o de terceros, ante un peligro inminente de muerte o de lesiones graves, cuando se presuma verosímilmente la existencia de armas de fuego o cuando pueda haber agresiones mortales aun sin ellas" (Perfil, 2018). Según la Ministra de Seguridad, como se consigna en la misma nota: "El 
Presidente respalda la doctrina y cree que ayuda a clarificar situaciones en las que la justicia ha condenado injustamente a policías que actuaron en el cumplimiento de su deber".

En la misma conferencia agregaba: "Salimos de un paradigma zaffaroniano ${ }^{4}$ para pasar a uno donde la víctima es más importante que el victimario", y añadió: "En los últimos casos hemos logrado sacar de esa situación a una enorme cantidad de policías y gendarmes que iban a ser condenados como homicidas y terminaron absueltos porque explicamos cuál había sido la conducta. Estaban defendiendo al ciudadano" (Infocielo, 2018). También manifestó: "Queremos que al policía que actúa como policía se lo trate como policía y al que actúa como ladrón que se lo trate como ladrón. Muchas veces un policía actuó como policía y lo trataron como delincuente o como victimario, cuando era víctima".

Si el peligro es inminente, la policía, la gendarmería o la prefectura no tienen que dar la voz de alto, pueden disparar, donde la justificación de esa inminencia puede ser tan arbitraria y subjetiva como sujetos involucrados haya.

En ese sentido, durante toda la administración Macri se ha incrementado el número de casos donde las FF. Ss. federales y provinciales, actuando con arbitrariedad, han asesinado ciudadanas/os — especialmente jóvenes, varones y pobres- De acuerdo con la organización de la sociedad civil Coordinadora contra la Represión Policial e Institucional: "[...] hasta el año 2015 se registraba un muerto por acción de las fuerzas de seguridad cada 30 horas, pero esa esa cifra aumentó a uno cada 28 horas en 2016. A lo largo de ese año, bajó a uno cada 25 horas y a 23 horas en 2017. Según la Correpi, desde 2015 y hasta 2019 los fallecidos alcanzaron la cifra de 1.303, uno cada 21 horas en promedio" (Perfil, 2019).

\footnotetext{
4 En relación con el nombre de un exministro de la Corte Suprema de Justicia, constitucionalista reconocido, Zaffaroni, donde en Argentina se lo asocia con toda interpretación jurídica que dé prioridad al Estado de derecho y los derechos humanos en el cumplimiento de la ley, frente a cualquier tipo de delito. También se lo suele denominar "modelo garantista".
} 


\section{I María Eugenia Cardinale}

Hacemos referencia a víctimas por 'gatillo fácil' —esto es, abuso en el uso de armas de fuego por las FF. Ss. en la vía pública— durante detenciones o en protestas sociales. La mayoría de los casos donde se produjeron muertes civiles en lugares de detención no estaban encerrados por un delito, sino de forma arbitraria.

Entendemos, por ello, que la definición del Otro interno en tanto identificación de peligro, es decir, los actores concretos del fenómeno identificado como sujeto amenazante de seguridad, viene dada por posiciones socioeconómicas: los sectores pobres y marginales urbanos, con mayor énfasis en las juventudes. Observamos como parte de esta lógica la presentación al Congreso de un proyecto para bajar la edad de imputabilidad a menores de 15 años, en 2019, tema que se ha puesto en debate desde el año 2016. Dada la grave crisis económico-financiera en que está inmersa Argentina, este tipo de proyectos no ha avanzado, pero la intención era continuar un camino punitivista.

El Presidente, en campaña por la reelección 2019, explicitaba los "sectores sociales peligrosos" publicando en Twitter lo siguiente: "Ellos son los máximos enemigos del cambio", y enumeraba: los burócratas, los matones, los vagos, los corruptos, los delincuentes, los narcotraficantes, entre otros (El País, 2019). En Argentina, decir 'vagos' refiere a desempleados estructurales, familias en situación de vulnerabilidad que reciben ayuda social del Estado, personas que viven de trabajo precario intermitente (changas). Es decir, sectores sociales vulnerables.

Ese discurso conservador, estigmatizante y polarizante, se sustenta en el 'repertorio semántico' de las clases privilegiadas y las clases medias (principales votantes de Cambiemos/Juntos por el Cambio), se direcciona hacia estos sectores de apoyo, los cuales se constituyen en la 'audiencia habilitadora' de los procesos de securitización.

\section{Brasil y la derecha ultraconservadora}

Bolsonaro asume la Presidencia de Brasil en enero de 2019. Se trata de un exmilitar, con años de pertenencia parlamentaria y con un 
historial de declaraciones extremas, conservadoras y militaristas. En el año 2016 se produjo la destitución de la presidenta electa, Rousseff, del Partido de los Trabajadores (PT), mediante un impeachment, cuestionado internacional e internamente e identificado por muchos como golpe institucional. La acusación fue de corrupción, razón por la cual el expresidente Da Silva, también del PT, ha sido procesado y encarcelado. ${ }^{5}$

En términos discursivos, Bolsonaro eligió como uno de los enemigos políticos y responsable de los males del país al "comunismo", concepto con el cual designa a los miembros del PT. Lo cierto es que sus enunciados securitarios, al igual que los de Macri, se fundamentan en la culpabilidad de los gobiernos progresistas anteriores por descuidar la seguridad pública. Un dato concreto lo contradice: en 2017 creció fuertemente la tasa de homicidios en Brasil, a pesar de la militarización de ciudades conflictivas como Río de Janeiro. No estaba en el gobierno el PT, sino un representante de la derecha: Temer.

En 2017 la cantidad de personas asesinadas en Brasil fue de 63880, 175 al día, de acuerdo con el informe del Foro Brasilero de Seguridad Pública (FBSP). Esta es la base para los discursos securitarios de Bolsonaro, posicionando al crimen organizado como la amenaza principal. Lo que no ha considerado el Presidente es que, de esa cifra, 5159 muertes violentas fueron en intervenciones policiales, 14 civiles por día, en contrapartida, las fuerzas de seguridad o militares contabilizaron 1 muerte violenta por día (El Español, 2019; Forum Seguranca, 2019).

En 2018, la tasa de homicidio por cada 100000 habitantes disminuyó a 27,5 , con un total de fallecimientos violentos intencionales

\footnotetext{
5 Recientemente se ha producido un escándalo público relacionado con la objetividad de la investigación y proceso judicial de corrupción conocido como Lava Jato (que ha involucrado altos mandos gubernamentales y empresarios) cuando el periódico The Intercept Brazil tuvo acceso a escuchas telefónicas y mensajes de celular del juez a cargo de ese proceso, Moro - actual Ministro de Justicia—, dando cuenta de la arbitrariedad del juicio y de la presión al fiscal para orientar el procedimiento contra una de las partes, el expresidente ( $E l$ Pais, 2019).
} 
de 57341 . De entre esos datos, 11 de cada 100 fueron provocadas por la policía, 6220 víctimas en 2018 (Forum Seguranca, 2019), un crecimiento del 19,6\% respecto al año anterior. Si bien, de acuerdo con el informe de la UNODC, la situación se volvió más grave en los últimos años, Brasil no está en los primeros escalones de la tabla de tasa de homicidios elaborada por el organismo para América Latina.

El FBSP también da cuenta de la composición étnica, etaria y de género en relación con esa población civil asesinada en operativos de seguridad: un 99,3\% varones; en un 77,9\% entre 15 y 29 años; un 75,4\% negros (Forum Seguranca, 2019). Este es el sector poblacional interno identificado por Bolsonaro - y sus votantes - como pertenecientes al sujeto amenazante, similar a lo que sucede en Argentina, pero con el aditamento de la cuestión racial en Brasil.

De hecho, el actual Presidente había declarado, en 2017, sobre los afrodescendientes en comunidades quilombolas (descendientes de esclavos): " ¡No hacen nada! Creo que ni para procrear sirven ya. Más de 1 billón de reales gastado al año en ellos" (BBC Mundo, 2018b). Si recordamos las promesas 3, 4 y 5 de campaña y las ponemos en vinculación con otras declaraciones - $\mathrm{y}$ con los datos de civiles asesinados en operativos de seguridad-, encontramos que aquellas dan cuenta de una tendencia a la discriminación de determinadas minorías y sectores vulnerables de Brasil.

La composición del gabinete de gobierno, por otra parte, habla del rol que otorga el Presidente a los militares: ocho de esos puestos estaban ocupados por militares o exmilitares al momento de asumir. Bolsonaro ha reivindicado públicamente, primero en campaña y luego en el gobierno, la dictadura militar brasilera iniciada en 1964. En marzo de este año dio la orden de conmemorar el golpe de Estado — que él niega que sea tal—, definiéndolo como "época gloriosa" de la historia, aun con sus problemas (El Ciudadano, 2019).

Contando con la legitimidad de origen que otorga el voto popular en los primeros meses de mandato, Bolsonaro se dispuso a cumplir 
con sus dos primeras propuestas securitarias de la agenda de campaña: relajar los controles y limitaciones para la compra de armas, y dar prerrogativas a las fuerzas de seguridad y militares en el uso de armas de fuego para combatir el crimen. Ya en su asunción del mando expresaba su deseo de facilitar la posesión de armas a los "ciudadanos de bien".

La primera de esas propuestas se presentó mediante decreto presidencial el 7 de mayo de 2019, buscando aumentar el número de armas de fuego por ciudadano/a (4), siempre que cumpla con los requisitos preestablecidos en la legislación de 2003: "Mayores de 25 años, estén legalmente empleados, no tengan casos penales pendientes o hayan sido condenados, tengan una residencia fija y la capacidad técnica y psicológica para usar el arma" (Hinz, 2019). Agrega a ello un componente más, la ampliación de los permisos para portación de armas en la vía pública: "Según el nuevo texto, no solo los coleccionistas de armas, tiradores deportivos y cazadores, sino también abogados, camioneros o políticos — desde los concejales municipales hasta el propio presidente- están exentos de demostrar su necesidad de portar un arma, y se les permite llevar un arma cargada mientras ejercen su profesión" (Hinz, 2019).

Por otra parte, el ministro de Justicia Moro — juez que llevó adelante la causa por corrupción más grande de las últimas décadas en Suramérica- presentó ante el Congreso, en febrero, un proyecto conocido como "paquete de leyes anticrimen", que vendría a modificar catorce leyes existentes. "Según la nueva propuesta, cualquier agente de seguridad que 'en un conflicto armado o en riesgo inminente de conflicto armado evita una agresión injusta e inminente' está actuando en defensa propia. Tal formulación permitiría al juez no solo relajar las penas por excesos cometidos en operaciones armadas, sino también aumentar la impunidad por los asesinatos cometidos por policías en Brasil” (Hinz, 2019).

Esto se propone en un escenario donde la muerte de población civil a manos de la policía o fuerzas militares ha mantenido un crecimiento constante. Una medida similar a la denominada 'Doctrina Chocobar' 
en Argentina. De acuerdo con el diario ElEspañol (2019): “Moro planea exculpar a los policías que maten a criminales 'por miedo, sorpresa, o emoción violenta". En campaña, Bolsonaro declaraba en relación con el tema: "Un buen criminal es un criminal muerto" (Londoño \& Andreoni, 2018). También afirmaba: "Si alguien considera que quiero dar carta blanca para que la policía mate yo contesto: sí, es lo que quiero. Un agente que no dispara a nadie y al que disparan todo el rato no es policía. Tenemos la obligación de ofrecer una seguridad jurídica a esos valientes [...] la policía puede disparar y si, por casualidad, el criminal se muere, paciencia" (Hinz, 2019).

En febrero de 2018, el Ejército tomó el control de la seguridad en Río de Janeiro, tiempo en el cual se ha dado el aumento de civiles asesinados en operativos de seguridad. Un dato relevante — sumado a que es considerado por Bolsonaro como modelo y que es su región de origen- es que allí operan, a la par de los grupos de negocios ilegales (con capacidad de ejercicio de la violencia), milicias privadas que en sus inicios ofrecían servicios de seguridad a determinados vecindarios: "Gran parte de la violencia en Río de Janeiro se debe a los grupos delincuenciales conocidos como milicias, formados por policías y militares retirados y en activo que actúan por cuenta propia. Se han vuelto cada vez más poderosos en comunidades desatendidas por el Estado pues extorsionan a los residentes a cambio de protección, operan negocios de transporte público sin licencia y se involucran en el narcomenudeo" (Londoño \& Andreoni, 2018).

Crespo (2019) sostiene que la familia Bolsonaro mantiene vínculos directos con estas milicias en Río de Janeiro. Amén de su exactitud, es significativo que no se hace mención a estos sectores responsables de la violencia en los discursos securitarios gubernamentales.

Otra medida securitizante, a pocos días de asumir el cargo, fue el despliegue en el Estado de Ceará de las FF. AA., por el incremento de la violencia, militarizando dicho territorio (BBC Mundo, 2019), evidenciando en la práctica su objetivo de 'mano dura' para el tratamiento del crimen y el conflicto social. 
A diferencia de Argentina, la Constitución de Brasil habilita el uso de las FF. AA. para el orden interno en determinados casos necesarios para el orden público, el punto relevante es que en una lógica punitivista y militarista ese uso puede volverse excesivo ante cualquier situación de conflicto social.

Mientras el "paquete de leyes anticrimen" sigue en debate en el Parlamento, el Congreso brasilero ha desestimado el decreto presidencial sobre flexibilización en la portación de armas (Guzmán, 2019), dando muestra de un desgaste en esa legitimidad de origen que garantiza el triunfo en comicios presidenciales.

Dentro de las primeras medidas de gobierno, Bolsonaro ha buscado aprovechar el consenso otorgado por las elecciones para avanzar en un proceso de securitización efectivo, a partir del movimiento para ello iniciado con las promesas de campaña. Claramente posicionado como actor securitizador, definió el sujeto amenazante y el objeto referente, este es asociado a la propiedad y la vida de "los ciudadanos de bien". Medidas extraordinarias, ampliatorias de las prerrogativas estatales para el uso de la fuerza y la violencia privada favorecida para determinado sector social, han sido promovidas desde el primer día de gobierno.

\section{Similitudes y diferencias de los casos estudiados}

Podemos resaltar como coincidencia el estrechamiento automático de relaciones bilaterales con Estados Unidos y el alejamiento de acuerdos de seguridad y defensa subregionales. Se produjo un fortalecimiento del vínculo en cooperación militar y policial con la potencia hemisférica. Señalamos esto como relevante dado que conforma el contexto externo que ha facilitado y fundamentado el proceso securitizador en ambos casos.

Durante el primer año de mandato de Macri, el entonces presidente estadounidense, Obama, hizo una visita oficial marcando el nuevo acercamiento bilateral. En la hoja de ruta trazada para seguridad y 
defensa, destacan los temas mencionados al inicio: combate al crimen organizado y al narcotráfico, agenda común y trabajo conjunto en mantenimiento de la paz, respuesta a desastres naturales, cooperación hemisférica en defensa (Barreto, 2018).

Temáticas que durante la década anterior eran tratadas a nivel subregional, particularmente en Unasur, y con un alejamiento de Argentina en la cooperación directa con Estados Unidos, fueron ahora orientadas hacia lo hemisférico y/o bilateral con el gobierno estadounidense.

Por otra parte, la coincidencia de temas prioritarios para la seguridad entre Brasil y Argentina no se tradujo necesariamente en instancias de cooperación bilateral, como venía sucediendo desde comienzos del siglo XxI. Brasil, al igual que Argentina, a partir del gobierno de Temer viene generando un vínculo estrecho con Estados Unidos, con acuerdos similares a los mencionados para su país vecino. Allí el alineamiento automático es más significativo dado que los gobiernos del PT habían logrado constituir a Brasil como un actor internacional con peso propio, con gran margen de autonomía y relaciones multilaterales importantes (Cardinale, 2018a).

Bolsonaro visita la Casa Blanca en marzo de 2019 como primer encuentro intergubernamental oficial, un acto simbólico de sus prioridades. Entre lo comunicado por ambos mandatarios se encuentra la "lucha contra el socialismo" en el hemisferio, identificado principalmente con Venezuela. Brasil fue declarado aliado extra-OTAN de Estados Unidos en temas de defensa y seguridad, en junio de 2019 (Argentina lo es desde la década de 1990).

El acoplamiento de ambos gobiernos a los requerimientos de seguridad de Estados Unidos puede observarse en lo mencionando como procesos de securitización en Argentina y Brasil. La forma de entender las nuevas amenazas, el rol de las FF. AA. para diversas problemáticas intermésticas (desde migraciones hasta cambio climático, pasando por el terrorismo y el crimen organizado) dan cuenta de una recepción total de los enunciados hegemónicos en seguridad. 
La cooperación entre ambos Estados en términos de seguridad la encontramos en la Triple Frontera, en la alianza antiterrorista firmada por Argentina, Brasil y Paraguay con Estados Unidos (como propuesta de este último). En la última conferencia hemisférica de lucha contra el terrorismo, en 2019, se estableció la renovación de la alianza contra 'actividades ilícitas' en la subregión, en especial en sus vínculos con el terrorismo, en la que Estados Unidos “[...] identifica a Irán y a la organización islamista libanesa Hezbolá como principales amenazas" (Romano et al., 2019).

No hay pruebas reales de la existencia de terrorismo o 'células dormidas' terroristas en la Triple Frontera, no obstante, este es el discurso sostenido desde hace años por Estados Unidos — que encontró reticencias en los Estados de la región durante las décadas pasadas- y que hoy parece asumirse sin cuestionamientos por los gobiernos conservadores de la subregión.

Las coincidencias parecen multiplicarse: desde sus campañas electorales se identificaba el sujeto amenazante y la necesidad de medidas urgentes; ambos gobiernos pueden ser reconocidos como actores securitizadores, no solo por los enunciados presidenciales, sino también por los de distintos miembros de sus gabinetes; los dos casos propician como herramientas medidas extraordinarias: por un lado, una mayor utilización de las FF. AA. en el orden interno dada la naturaleza acuciante de la amenaza; por otro, mayores prerrogativas a las fuerzas militares y/o de seguridad en el uso de la fuerza; destacan el centramiento en lo doméstico para focalizar el proceso de securitización y la pérdida de gravitación de la cooperación subregional; la tendencia hacia al punitivismo, la mano dura y la militarización del orden público (con las consecuentes denuncias de abuso policial/militar) y una percepción del Estado de derecho flexibilizada, especialmente con respecto a los derechos procesales y garantías legales hacia aquellos identificados como delincuentes o criminales, tal como pudo observarse en los discursos gubernamentales citados.

En los dos casos la centralidad otorgada a la seguridad parece vincularse con la intención de posicionarse en el otro extremo del espectro político de sus principales oponentes (FPV y PT), los cuales han dado 
un lugar destacado de enunciación y de decisión a los DD. HH., con énfasis en los de segunda generación. Bolsonaro y Macri coinciden en contraponer la defensa de los derechos de las mayorías a las necesidades de seguridad, al uso de la fuerza frente a la criminalidad y a los problemas securitarios que acarrea un modelo 'garantista'.

Estas tendencias se acercan a las prácticas de otros Estados latinoamericanos más conservadores y aliados tradicionales de Estados Unidos, como Perú, Colombia, Paraguay y Chile. Se produjo entre los seis Estados una convergencia para abandonar Unasur, denunciar al gobierno de Maduro (propiciando una intervención directa en el caso de Macri) y defender un modelo neoliberal estricto de gestión económica, sumado a un enfriamiento del Mercosur en los casos de Argentina y Brasil.

Por otra parte, identificamos diferencias: en primer lugar, en las condiciones contextuales internas, si bien en Argentina pueden encontrarse reclamos crecientes por la inseguridad por parte de la ciudadanía (principalmente asociados a robos violentos), los niveles de violencia y criminalidad social son bajos en contraposición al resto de Latinoamérica, de allí que seleccionar el narcotráfico como amenaza urgente (y la seguridad como prioridad) guarde mayor relación con percepciones ideológicas y afectivas que con datos objetivos.

En segundo lugar, encontramos diferencias enunciativas, asociadas a la ciudadanía y la potencial audiencia securitizante en cada país. Bolsonaro tiene un discurso más extremo, abiertamente discriminatorio, militarista y religioso explícito. La historia democrática de Brasil es institucionalmente más débil, las FF. AA. han tenido un rol de primacía dentro del Estado y no hubo condena mayoritaria a la última dictadura militar; la defensa de la democracia no está arraigada colectivamente en la población como en Argentina. Esto significa que existe un margen importante de audiencia favorable a la desestimación de la institucionalidad democrática o los DD. HH., como suele hacer Bolsonaro en sus declaraciones.

Al comprender los enunciados como dialógicos, el rol de las audiencias es clave, Bolsonaro apela a sectores sociales que se definen por su fuerte 
religiosidad cristiana, su posición en la escala de estratificación social y la diferenciación racial. Dichos sectores comparten una evaluación moral de lo político y una carga afectiva conservadora del orden social y también de la democracia, son las fuerzas sociales convocadas a dar legitimidad a un endurecimiento del uso de la fuerza y el control social, a una desestimación de ciertos aspectos del Estado de derecho y a una exaltación de lo militar. Lo más extremo de esta posición nos parece el apoyo popular a la habilitación para el uso de armas de fuego del sector privado como respuesta al crimen organizado.

El caso de Macri ha sido diferente, en particular por la historia democrática argentina — su restauración a partir del juzgamiento a los militares responsables del golpe de Estado, los juicios por crímenes de lesa humanidad de los involucrados y el rechazo a la última dictadura-, que reviste un consenso mayoritario en la ciudadanía (con matices). Por lo tanto, el discurso debió ser más moderado para obtener apoyos de la audiencia securitizadora, aunque puedan interpretarse los mismos objetivos de criminalización de segmentos sociales vulnerables (particularmente por el destino de las medidas securitarias contra el narcotráfico, cuyo eje ha sido el narcomenudeo en las grandes ciudades), puesta en valor de las FF. AA. para la seguridad interna y vínculos con sectores religiosos (pero de forma más velada). En todo caso, el 'repertorio semántico' aceptable para estas audiencias conservadoras argentinas puede orientarse hacia una democracia de más baja intensidad y mayor 'mano dura', pero no a una exaltación de las FF. AA.

La apelación afectiva y ético-política en este caso tendió a vincular DD. HH. con un interés particular (no universal) del kirschnerismo (un "curro") y, por lo tanto, a su desestimación como prioridad de gobierno; a la revalorización de la seguridad para garantir la propiedad privada y la vida cotidiana de los estratos sociales altos y medios; y a una institucionalidad democrática limitada estrictamente a lo formal, problematizando los límites legales del poder político.

La propia utilización de las FF. AA. es diferente por limitantes constitucionales en Argentina, donde no pueden intervenir provincias o zonas como hace habitualmente Brasil (práctica incrementada bajo el gobierno 
de Bolsonaro). Sin embargo, el proceso de securitización llevó a la utilización de FF. Ss. especializadas y militarizadas argentinas para intervenir en la gestión de la seguridad pública en las provincias de forma habitual.

Con respecto a los actores peligrosos considerados dentro del sujeto amenazante, la diferencia radica principalmente en la relevancia de la cuestión racial en Brasil, mientras que en Argentina se centraba más en las condiciones socioeconómicas de determinados sectores y, en muchos casos, en sus vínculos con organizaciones sociales afines al gobierno de Fernández.

Los límites institucionales y sociales de Argentina restringieron los enunciados securitarios y las medidas posibles, sin embargo, identificamos una diferencia solo de matices entre ambos, con una coincidencia en el plano general acerca de la seguridad, los objetivos del Estado, la búsqueda de una democracia flexibilizada y la criminalización de determinados segmentos sociales, bajo un modelo punitivista y represivo.

En la tabla 1 se esquematizan las diferencias y similitudes de ambos procesos de securitización.

Tabla 1. Securitización en Argentina y Brasil

\begin{tabular}{|l|l|l|}
\hline & \multicolumn{1}{|c|}{ Argentina } & \multicolumn{1}{c|}{ Brasil } \\
\hline $\begin{array}{l}\text { Actor } \\
\text { securitizador }\end{array}$ & Gobierno nacional & Gobierno nacional \\
\hline $\begin{array}{l}\text { Amenaza } \\
\text { existencial }\end{array}$ & Narcotráfico & Crimen organizado \\
\hline $\begin{array}{l}\text { Sujeto } \\
\text { amenazante (parte } \\
\text { de la amenaza) del } \\
\text { enunciado }\end{array}$ & $\begin{array}{l}\text { Vagos', narcotraficantes, } \\
\text { delincuentes. }\end{array}$ & Inútiles, criminales. \\
\hline $\begin{array}{l}\text { Audiencias } \\
\text { habilitadoras }\end{array}$ & $\begin{array}{l}\text { Propietarios, trabajadores } \\
\text { (autopercibidos, más allá } \\
\text { de la condición formal), } \\
\text { ciudadanía (categoría } \\
\text { restringida arbitrariamente, } \\
\text { no revisten igual condición } \\
\text { quienes son catalogados } \\
\text { como delincuentes). }\end{array}$ & $\begin{array}{l}\text { Propietarios, trabajadores, } \\
\text { "ciudadanos de bien" (definición } \\
\text { arbitraria del Presidente, } \\
\text { no revisten igual condición } \\
\text { quienes están catalogados como } \\
\text { criminales), cristianos evangélicos } \\
\text { (fuente de apoyo político } \\
\text { fundamental a Bolsonaro). }\end{array}$ \\
\hline
\end{tabular}




\begin{tabular}{|c|c|c|}
\hline & Argentina & Brasil \\
\hline $\begin{array}{l}\text { Medidas } \\
\text { extraordinarias }\end{array}$ & $\begin{array}{l}\text { - Mayor margen de uso de } \\
\text { armas para las fuerzas } \\
\text { de seguridad frente a la } \\
\text { inminencia de peligro } \\
\text { o violencia (Doctrina } \\
\text { Chocobar). } \\
\text { - Habilitación del uso } \\
\text { de las FF. AA. para } \\
\text { seguridad interna (por } \\
\text { decreto presidencial, } \\
\text { inconstitucional), Ley de } \\
\text { Emergencia en Seguridad } \\
\text { año } 2016 \text { (limitada a } \\
\text { fronteras en los hechos). }\end{array}$ & $\begin{array}{l}\text { - Mayor margen de uso de armas } \\
\text { para las fuerzas de seguridad } \\
\text { frente a la inminencia de } \\
\text { peligro o violencia (paquete de } \\
\text { leyes anticrimen). } \\
\text { - Intensificación del uso de } \\
\text { las FF. AA. para mantener el } \\
\text { orden público (prerrogativa } \\
\text { constitucional). Intervención } \\
\text { en Estados federados. } \\
\text { - Presentación de ley para } \\
\text { ampliar el número de armas } \\
\text { en tenencia por ciudadanos/ } \\
\text { as privados habilitados y } \\
\text { mayor número de personas } \\
\text { autorizadas para portar } \\
\text { armas en la vía pública } \\
\text { (se incorporaron a la ley: } \\
\text { transportistas, funcionarios } \\
\text { públicos, entre otros). } \\
\text { Decreto no aprobado por el } \\
\text { Parlamento. }\end{array}$ \\
\hline Contexto & $\begin{array}{l}\text { - Desestimación de } \\
\text { instancias de cooperación } \\
\text { subregional en defensa } \\
\text { y seguridad: retiro } \\
\text { de Unasur, menores } \\
\text { acuerdos bilaterales con } \\
\text { Brasil y enfriamiento del } \\
\text { Mercosur. Alineamiento } \\
\text { con Estados Unidos y sus } \\
\text { prioridades securitarias } \\
\text { (nuevas amenazas, } \\
\text { mutlidimensionalidad y } \\
\text { condición interméstica). } \\
\text { Orientación hemisférica } \\
\text { —o con participación } \\
\text { estadounidense- de } \\
\text { la cooperación en la } \\
\text { temática. } \\
\text { - Oposición al gobierno } \\
\text { de Venezuela (Grupo de } \\
\text { Lima). }\end{array}$ & $\begin{array}{l}\text { - Desestimación de instancias } \\
\text { de cooperación subregional } \\
\text { en defensa y seguridad: retiro } \\
\text { de Unasur, menores acuerdos } \\
\text { bilaterales con Argentina y } \\
\text { enfriamiento del Mercosur. } \\
\text { Alineamiento con Estados } \\
\text { Unidos y sus prioridades } \\
\text { securitarias (nuevas amenazas, } \\
\text { multidimensionalidad y } \\
\text { condición interméstica). } \\
\text { Orientación hemisférica } \\
\text { —o con participación } \\
\text { estadounidense- de la } \\
\text { cooperación en la temática. } \\
\text { - Oposición al gobierno de } \\
\text { Venezuela (Grupo de Lima). }\end{array}$ \\
\hline
\end{tabular}




\begin{tabular}{|c|c|c|}
\hline & Argentina & Brasil \\
\hline $\begin{array}{l}\text { Repertorio } \\
\text { semántico }\end{array}$ & $\begin{array}{l}\text { - Desestimación de los } \\
\text { DD. HH. (“curro") como } \\
\text { algo identificado con el } \\
\text { gobierno anterior, no } \\
\text { universal. } \\
\text { - Necesidad de 'mano } \\
\text { dura', fin de políticas } \\
\text { 'garantistas'. } \\
\text { - Flexibilidad de la } \\
\text { división de poderes y } \\
\text { de la institucionalidad } \\
\text { democrática. } \\
\text { - Intentos de } \\
\text { criminalización de } \\
\text { movimientos originarios, } \\
\text { como la comunidad } \\
\text { mapuche. } \\
\text { Negación del número de } \\
\text { desaparecidos durante la } \\
\text { dictadura, flexibilización } \\
\text { del discurso al referirse } \\
\text { a ese período. Retorno } \\
\text { de los desfiles militares } \\
\text { para fechas patrias y actos } \\
\text { oficiales. } \\
\text { Discurso anticorrupción } \\
\text { (a pesar de las denuncias } \\
\text { a funcionarios macristas) } \\
\text { frente a las acusaciones de } \\
\text { corrupción del anterior } \\
\text { gobierno y las causas } \\
\text { abiertas a exfuncionarios. }\end{array}$ & $\begin{array}{l}\text { - Desestimación de los DD. HH. } \\
\text { y de leyes de inclusión (de } \\
\text { géneros y disidencias, planes } \\
\text { sociales, etc.). } \\
\text { - Necesidad de aumentar el } \\
\text { uso de la fuerza contra los } \\
\text { criminales, militarización. } \\
\text { - Criminalización de } \\
\text { movimientos sociales, } \\
\text { definición del P'T y grupos } \\
\text { afines como peligro comunista. } \\
\text { - Exaltación de las FF. AA. } \\
\text { - Defensa y ensalzamiento de la } \\
\text { dictadura brasilera. } \\
\text { - Discurso anticorrupción frente } \\
\text { a las denuncias y juicios por } \\
\text { corrupción a miembros del } \\
\text { anterior gobierno. }\end{array}$ \\
\hline
\end{tabular}

\section{Conclusiones}

A lo largo del trabajo hemos seleccionado en los discursos de seguridad de Macri y Bolsonaro elementos que nos permitan posicionarlos como actores securitizadores, esto es, instalando en la agenda política la urgencia de una amenaza existencial. Se ha podido corroborar que el narcotráfico y sus vínculos con el crimen organizado en Argentina 
y este último - en su asociación a altos niveles de violencia social en Brasil- operaron como los peligros inmediatos por enfrentar en los enunciados presidenciales.

Instalar un discurso securitario e identificar la amenaza en las campañas electorales supuso la obtención de consenso para iniciar el proceso securitizador al momento de asumir el cargo, con dos modalidades básicas que se pueden apreciar en los casos bajo análisis: una escalada de los enunciados securitizadores en las declaraciones de ambos presidentes y sus funcionarios, y una modificatoria de instrumentos legales existentes que permitieran medidas extraordinarias, en particular para el uso de la fuerza por parte del Estado. En el caso de Brasil se presenta, además, la particularidad de alegar la legítima defensa ciudadana para compra y portación pública de armas personales.

Las prácticas excepcionales se llevaron a cabo principalmente contra un sector social calificado como los agentes representativos del sujeto amenazante. Hemos encontrado en los discursos y la aplicación de la violencia estatal una tendencia a la represión de jóvenes pobres urbanos, con el aditamento en Brasil de una consideración racial.

La defensa es hacia sectores conservadores, de estratos altos, medios y medio bajo, insertos en el sistema y subordinados a las reglas de juego neoliberales, votantes de ambos candidatos que operaron como 'audiencias securitizantes', en contraposición a los sujetos detrás de la amenaza — retratados como "vagos" por Macri e inútiles por Bolsonaro- Hablamos de los excluidos de esas reglas de mercado, los vulnerables y marginados.

Se produce la estigmatización y criminalización de determinados grupos sociales, como Otro interno, a la par de la aplicación de políticas económicas neoliberales que recortan cualquier espacio de inserción de las poblaciones vulnerables: ajustes en educación, salud, sistemas de pensiones, etc. Se ponen en juego aspectos subjetivos e ideologizados para definir tanto la seguridad como la amenaza, definiciones "autorreferenciales" que hacen uso de evaluaciones afectivas y éticopolíticas (Lazzarato, 2006), y pueden ser inscriptas en la tradición de 
un determinado "repertorio semántico" (Balzacq et al., 2015) para las audiencias. Las medidas apuntan a los escalones más bajos de las cadenas ilegales, por ejemplo, Argentina destaca en el lavado de dinero y, sin embargo, el gobierno macrista defendió una apertura irrestricta del mercado financiero. Una amenaza transnacional, al ser referida como existencial y urgente, introduce una interpretación interméstica de la seguridad asociada a la militarización del orden interno, dando poder de intervención a las FF. AA. en mayores temas y problemáticas. Mientras que en Brasil el crimen organizado tiene un alto poder de fuego y control territorial urbano desde hace años, en Argentina la selección de la amenaza no se condice con la realidad del narcotráfico en el país, su apelación parece operar como justificación enunciativa para la aplicación de un proceso de securitización social. De todas maneras, la mayor securitización y criminalización social en Brasil no tuvo como contrapartida una disminución de la violencia ni de las capacidades del crimen organizado.

Los procesos securitarios se manifiestan como insuficientes para sostener el consenso de las mayorías frente a situaciones económicas adversas, que en el caso de Argentina escala a crisis exponencial; el bienestar social parece tener un peso mayor para las y los ciudadanos suramericanos. La imagen pública de Bolsonaro se ha deteriorado a pasos acelerados en los últimos meses y Macri, por su parte, ha perdido las elecciones primarias por un margen muy grande de votos. De continuar estas tendencias, estamos ante la caída de la securitización social instalada que supone como condición sine qua non el respaldo efectivo de determinadas audiencias.

\section{Referencias}

( $1^{\circ}$ de marzo de 2016). Discurso completo de Mauricio Macri ante la Asamblea Legislativa. La Nación. Recuperado de https://www.lanacion.com. ar/politica/discurso-completo-de-mauricio-macri-ante-la-asamblea-legislativa-nid1875715

(10 de agosto de 2016). Macri llamó "guerra sucia" a la última dictadura y dijo desconocer si eran "9 mil o 30 mil los desaparecidos". La Capital. 
Recuperado de https://www.lacapital.com.ar/politica/macri-llamoguerra-sucia-la-ultima-dictadura-y-dijo-desconocer-si-eran-9-mil-o30-mil-los-desaparecidos-n1206372.html

(28 de octubre de 2018a). Jair Bolsonaro gana en Brasil: 5 polémicos proyectos del presidente electo. BBC Mundo. Recuperado de https:/ / www. bbc.com/mundo/noticias-america-latina-45981230

(28 de octubre de 2018b). Jair Bolsonaro gana en Brasil: 7 frases que reflejan el pensamiento político, social y económico del nuevo presidente electo. BBC Mundo. Recuperado de https://www.bbc.com/mundo/ noticias-america-latina-45969725

(6 de diciembre de 2018). Patricia Bullrich aseguró que la "doctrina Chocobar" tiene el respaldo del presidente Macri. Infocielo. Recuperado de https://infocielo.com/nota/99192/patricia_bullrich_aseguro_que_ la_doctrina_chocobar_tiene_el_respaldo_del_presidente_macri/

(6 de enero de 2019). Brasil: Bolsonaro envía tropas a Fortaleza para frenar la ola de violencia. BBC Mundo. Recuperado de https:/ /www.bbc.com/ mundo/noticias-46775173

(24 de marzo de 2019). Bolsonaro cambia el mapa de América Latina tras sellar 'relaciones carnales' con Trump. Perfil. Recuperado de https:// www.perfil.com/noticias/internacional/bolsonaro-cambia-el-mapade-america-latina-tras-sellar-relaciones-carnales-con-trump.phtml

(8 de julio de 2019). Informe de la ONU. América Latina: la región con más homicidios del mundo por la desigualdad y el crimen organizado. Clarín. Recuperado de https://www.clarin.com/mundo/america-latinaregion-homicidios-mundo-desigualdad-crimen-organizado_0_zO5s$5 \mathrm{~V} 8 \mathrm{k} 6 . \mathrm{html}$

Argentina, Ministerio de Justicia y Derechos Humanos. Seguridad Pública. Decreto 228/2016. InfoLEG. Recuperado de http:/ /servicios.infoleg. gob.ar/infolegInternet/anexos/255000-259999/258047/texact.htm Assusa, G. (2019). ¿Hacia la criminalización de la niñez? El régimen penal juvenil argentino en debate. Nueva Sociedad. Recuperado de https:// nuso.org/articulo/juventud-carceles-edad-imputabilidad/imprimir/

Baeza, M. M. (2016). Securitización de las fronteras en América del Sur (2004-2014) (Tesis de maestría, Universidad Torcuato Di Tella, Argentina). Recuperado de https://repositorio.utdt.edu/bitstream/handle/utdt/2473/ MEI_2016_Baeza.pdf?sequence $=1$ \&isAllowed $=\mathrm{y}$ 
Balzacq, T., Léonard, S., \& Ruzicka, J. (2015). ‘Securitization’ revisited: theory and cases. International Relations, 30(4), 494-531. https://doi. org/10.1177/0047117815596590

Barreto, L. M. (2018). Conceptualizando las relaciones argentino-estadounidenses recientes en materia de seguridad y defensa. ¿Una relación de afinidades electivas? Relaciones Internacionales, 55, 165-176.

Buzan, B., Waever, O., \& Wilde de, J. (1998). Security: a new framework for analysis. UK: Lynne Rienner Publishers.

Buzan, B., \& Hansen, L. (2009) The evolution of international security studies. UK: Cambridge University Press.

Cardinale, M. E. (2017a). Derecho penal del enemigo, excepción política y securitización: contracaras de la seguridad. Revista Estudiantil Latinoamericana de Ciencias Sociales, 6(10). https://doi.org/10.18504/ r10110-001-2017

Cardinale, M. E. (2017b). Seguridad internacional y derechos humanos: una reflexión a partir de los aportes del cosmopolitismo crítico y el liberalismo ofensivo. Revista de Estudios en Seguridad Internacional, 3(1), 127-148. https://doi.org/10.18847/1.5.7

Cardinale, M. E. (2018a). La nueva coyuntura suramericana: crisis de Unasur y giro “conservador'. En Mariana P. Acevedo et al., III Jornadas de Investigación de la Facultad de Trabajo Social en el Contexto Latinoamericano (pp. 810-825). Universidad Nacional de Entre Ríos.

Cardinale, M. E. (2018b). Seguridad internacionaly derechos humanos: en busca de una mirada autónoma para América del Sur. Buenos Aires: Editorial Teseo.

Carelli, G. (13 de septiembre de 2015). Macri presentó sus tres ejes de campaña con los que espera llegar al balotaje. Clarín. Recuperado de https://www.clarin.com/politica/elecciones_2015-macri-propuestasbalotaje_0_HkWx7Xmtw7g.html

Casa Rosada. (30 de mayo de 2016). Palabras de Mauricio Macri en el $206^{\circ}$ Aniversario del Ejército Argentino. Recuperado de https://www.casarosada. gob.ar/informacion/discursos/36508-palabras-de-mauricio-macrien-el-206-aniversario-del-ejercito-argentino

Casa Rosada. (2019). Sección Seguridad y Narcotráfico. Recuperado de https://www.casarosada.gob.ar/2-uncategorised/39926-seguridady-narcotrafico 
Crespo, E. (2019). Brasil en el desarmadero. Nueva Sociedad. Recuperado de https://nuso.org/articulo/brasil-bolsonaro-derecha-militares-/ imprimir/

Dalby, C., \& Carranza, C. (2019). Balance de InSight Crime sobre los homicidios en 2018. InSight Crime. Recuperado de https://es.insightcrime.org/noticias/analisis/balance-de-insight-crime-sobre-los-homicidios-en-2018/

Eissa, S. (2018). Construyendo al enemigo: la securitización del reclamo mapuche. Perspectivas. Revista de Ciencias Sociales, 3(5), 35-61.

Fava, N. (5 de octubre de 2018). La Doctrina Chocobar. Bordes. Revista de Política, Derecho y Sociedad. Recuperado de http:// revistabordes.com. ar/la-doctrina-chocobar/

Fidanza, A. (8 de diciembre de 2018). El Gobierno ya puso en marcha el nuevo protocolo y busca que sea eje de campaña. Perfil. Recuperado de https://www.perfil.com/noticias/politica/el-gobierno-ya-puso-enmarcha-el-nuevo-protocolo-y-busca-que-sea-eje-de-campana.phtml

Frenkel, A. (2019). "Disparen contra las olas": securitización y militarización de desastres naturales y ayuda humanitaria en América Latina. Íconos, (64), 183-202. https://doi.org/10.17141/iconos.64.2019.3435

Frenkel, A. (noviembre de 2018). El mundo según Bolsonaro. La nueva política exterior de Brasil. Nueva Sociedad. Recuperado de https: / / nuso. org/articulo/el-mundo-segun-bolsonaro/

Gallo, D. (28 de mayo de 2015). Estadística. Cifras oficiales: creció 16\% el número de asesinatos en el país. La Nación. Recuperado de https:/ / www.lanacion.com.ar/seguridad/cifras-oficiales-crecio-16-el-numerode-asesinatos-en-el-pais-nid1796485/

Guzmán, P. (2019). Brasileños marchan contra apología de Bolsonaro a la dictadura militar. El Ciudadano. Recuperado de https:/ /www.elciudadano.com/latino-america/brasilenos-marchan-contra-apologia-debolsonaro-a-la-dictadura-militar/03/31/

Hinz, K. (2019). La nueva política de seguridad de Bolsonaro amenaza la vida de las mujeres negras y marginadas. Democracia Abierta. Recuperado de https://www.opendemocracy.net/es/democraciaabierta-es/novapol $\%$ C $3 \%$ ADtica-de-seguran $\% \mathrm{C} 3 \% \mathrm{~A} 7 \mathrm{a}$-de-bolsonaro-p $\% \mathrm{C} 3 \% \mathrm{~B} 5 \mathrm{e}$ em-risco-mulheres-negras-e-marginalizadas-es/

Jiménez, C., \& Rossi, M. (14 de junio de 2019). Bolsonaro destituye a su secretario de Gobierno en medio del escándalo de Sérgio Moro. El 
País. Recuperado de https://elpais.com/internacional/2019/06/13/ actualidad/1560425634_536159.html

Lajtman, T. (2019). EE. UU. y Brasil: defensa, seguridad y subordinación. Celag. Recuperado de https://www.celag.org/eeuu-y-brasil-defensa-seguridad-subordinacion/

Lazzarato, M. (2006). Políticas del acontecimiento. Buenos Aires: Tinta Limón.

Londoño, E., \& Andreoni, M. (1 de noviembre de 2018). "Cavaremos las tumbas": Brasil se alista para la política de seguridad de Bolsonaro. New York Times. Recuperado de https://www.nytimes.com/ es/2018/11/01/brasil-bolsonaro-seguridad-policia/

McDonald, M. (2008). Securitization and the construction of security. European Consortium for Political Research, 14(4), 563-587. https://doi. org $/ 10.1177 / 1354066108097553$

Oelsner, A. (2009). La amistad, la confianza mutua y la evolución de la paz regional en el sistema internacional. Miríada. Investigación en Ciencias Sociales, 2(3), 9-46. Recuperado de https://p3.usal.edu.ar/index.php/ miriada/article/view/397

Rei, J. (6 de febrero de 2019). El plan de seguridad de Bolsonaro: armar a civiles e indultar a policías que maten "por miedo". ElEspañol. Recuperado de https://www.elespanol.com/mundo/america/20190206/seguridad-bolsonaro-civiles-indultar-policias-maten-miedo/373963404_0. html

Romano, S., Lajtman, T., \& García Fernández, A. (2019). La Liga Antiterrorista del Sury la geopolítica de la Triple Frontera. Celag. Recuperado de https:/ /www.celag.org/la-liga-antiterrorista-del-sur-y-la-geopoliticade-la-triple-frontera/

Sain, M. (2018). ¿Los militares como policías? Cambios en la seguridad en Argentina 2013-2018. Nueva Sociedad. Recuperado de https:// nuso.org/articulo/los-militares-como-policias-seguridad-en-argentina-2013-2018/imprimir/

Tello, S. (2011). Revisando la securitización de la agenda internacional: la normalización de las políticas del pánico. Relaciones Internacionales, 18, 189-200.

Tickner, A. B. (2005). La securitización de la crisis colombiana: bases conceptuales y tendencias generales. Colombia Internacional, (60), 12-35. https://doi.org/10.7440/colombiaint60.2004.01 
Tokatlián, J. G. (2016a). ¿Argentina es el tercer exportador mundial de cocaína? Página 12. Recuperado de https://www.pagina12.com.ar/ diario/contratapa/13-304214-2016-07-14.html

Tokatlián, J. G. (2016b). La peligrosa estratagema de Macri de militarizar Argentina. InSigth Crime. Recuperado de https:/ / es.insightcrime.org/ noticias/analisis/peligrosa-estratagema-macri-militarizar-argentina/

Tokatlián, J. G. (2019). Argentina y el "militarismo neoliberal periférico". Nueva Sociedad. Recuperado de https://nuso.org/articulo/argentinay-el-militarismo-neoliberal-periferico/imprimir/

UNODC, ONU. (2015). Statistic and data. Global study on homicide. Recuperado de https://dataunodc.un.org/GSH_app

White House. (2011). Fact sheet: strategy to combat transnational organized crime. Recuperado de https://obamawhitehouse.archives.gov/the-pressoffice/2011/07/25/fact-sheet-strategy-combat-transnational-organized-crime 